\title{
COLON AND RECTAL INJURIES CAUSED BY HIGH VELOCITY PENETRATING TRAUMA: CAN WE STAND WITH THE CURRENT TRENDS?
}

\author{
Rajapaksha S K ${ }^{1}$, Sirisena K K D², Dissanayaka A N ${ }^{3}$, Wijesinghe $A^{4}$ \\ ${ }^{1}$ Registrar in Surgery, National Hospital, Colombo, ${ }^{2}$ Consultant Surgeon, Teaching Hospital, \\ Anuradhapura, ${ }^{3}$ Medical Officer, Teaching Hospital, Anuradhapura, ${ }^{4}$ Senior House Officer, \\ General Hospital, Trincomalee.
}

\begin{abstract}
Introduction: Management of colorectal injuries is still under debate. The purpose of this study was to analyze management and clinical outcome from a cohort of patients with colorectal injuries caused by high velocity missiles.

Objectives: This was a retrospective analysis of consecutively collected data from all the war zone casualties with colorectal injuries during a 6 month period from 14th April 2008 at Teaching Hospital, Anuradhapura.

Results: 21 patients were treated with colorectal injuries. Mode of treatment included primary repair and anastomosis $(57.15 \%)$, colostomy $(9.52 \%)$, primary repair with proximal loop colostomy (33.33\%). According to the location of the primary injury to the colon, colostomy was made frequently with rectal injuries (87.5\%) vs. colon (15.39\%). Morbidity rate was $14.28 \%$.

Conclusion: 1) Primary repair was the most common mode of treatment for colonic trauma. 2) Primary repair and proximal loop colostomy was a safe option for rectal trauma.
\end{abstract}

S K Rajapaksha MBBS

Registrar in Surgery,

National Hospital, Colombo.

K K D Sirisena MBBS, MS, FRCS (Edin)

Consultant Surgeon,

Teaching Hospital, Anuradhapura.

\section{Introduction}

The management of colorectal injuries is controversial $(1,2)$. Primary repair, resection and anastomosis, resection and end colostomy, primary repair or anastomosis with defunctioning colostomy are the available surgical options. Okies introduced the exteriorization of the repaired segment until healing has been demonstrated, but popularity has been lost due to increased rates of conversion to
A N Dissanayaka MBBS

Medical Officer,

Teaching Hospital, Anuradhapura.

A Wijesinghe MBBS

Senior House Officer, General Hospital, Trincomalee.

colostomy and obstruction (3). Currently the trend is toward primary repair and anastomosis $(2,4)$.

Due to the experience gained during military conflicts in the past, mortality rates following colorectal injuries are reducing since 1950 . With the experience of $60 \%$ mortality during World War 1, colostomy was mandated in World War II for all colorectal injuries and 30\% mortality rates were attributed to this. During the Korean and Vietnam War mortality 
rates were $10-15 \%$. This was attributed to development of antibiotics, resuscitation, earlier evacuation and operation, and development in other supportive care. $48 \%$ morbidity rates after these injuries are seen in Operation Iraqi Freedom (5). Currently major complication rates are ranging from $15-50 \%$.

With keeping above facts in mind here we discuss the outcome of colorectal injuries managed at Surgical Unit B, Teaching Hospital, Anuradhapura. This was a main centre for treating the patients of humanitarian missions in Sri Lanka.

\section{Patients and methods}

This is a retrospective analysis of 21 patients treated during a 6 month period (15 April 2008 to 15 Oct 2008). All the patients who had high velocity penetrating colorectal trauma are included. All these patients were male and military personals. They were in the age group of 20-38 years. None of them had medical co morbidities.

Rectum was the most commonly injured section of the large intestine $(\mathrm{n}=8)$ (Table 1$)$. Only one patient treated with primary repair alone. All the other rectal injuries had primary repair and proximal loop colostomy.

Most (6/7) of the right sided injuries were multiple or there were multiple terminal ileal injury, and underwent limited right hemicolectomy and enterocolic anastomosis. Five of those were iliocolic. One had associated mesenteric vascular injury with extensive ileal ischemia, and underwent ileal resection and jejunocolic anastomosis. Primary repair was done in one patient with $15 \mathrm{~mm}$ size injury.

3 of the transverse colon injuries were treated with primary repair or direct end to end anastomosis (Figure1). One was treated with a colostomy and a mucous fistula, as he was initially hemodynamically unstable.

Single descending colon injury in this study was primarily repaired.
Fashioning of the sigmoid injury to a loop colostomy done in one patient.

None of the patients had intraoperative bowel irrigation. Manual bowel evacuation done through the wounds in all possible cases. This was impossible in all the rectal cases as they were small.

Hand sewen 2 layer technique with 3/0 absorbable suture material was the method of repair and anastomosis.

All these patients had adequate washing of the peritoneal cavity with warm isotonic saline at the end of the procedure.

All the laporotomies were closed in standard manner.

\section{Results}

Primary repair was done in $84.68 \%$ of colonic injuries. $12.5 \%$ of patients with rectal injuries were treated by primary repair (Figure 1). Overall colostomy rate is $42.85 \%$.

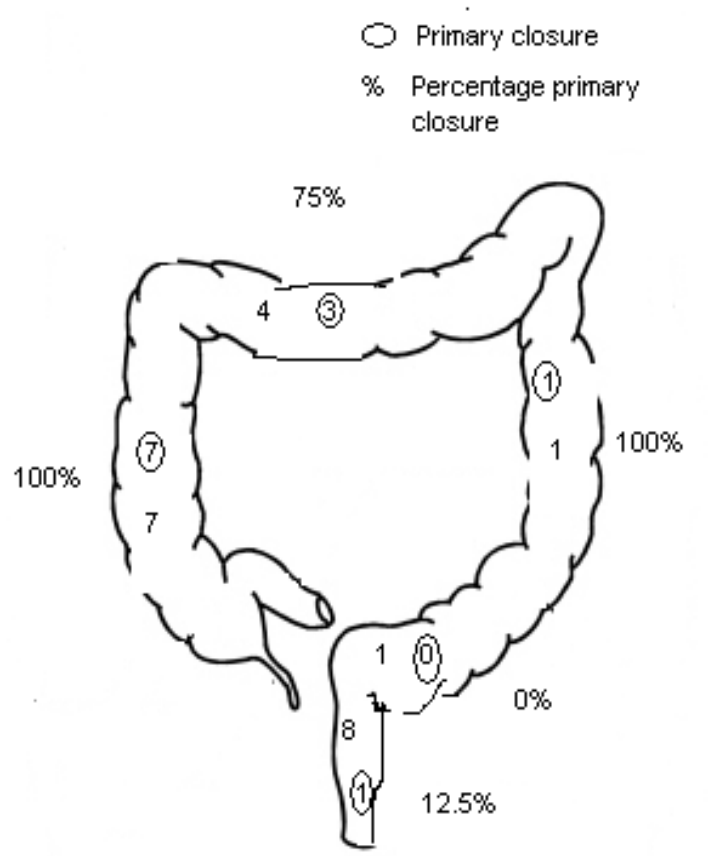

Figure 1. Location of colon injuries which were closed primarily with numbers and percentages. 
One patient who had jejunocolic anastomosis developed low output fistula. He underwent $2^{\text {nd }}$ laporotomy as there was sepsis and anastomotic dehiscence was repaired.

Two patients developed wound infections around the stoma in colostomy group.

There is one mortality within 24 hours. He had a pelvic fracture too.

\section{Discussion}

Swinging of the pendulum towards the primary repair and anastomosis from colostomy is seen during the past few decades in colorectal trauma treatment $(2,4)$.

Avoidance of colostomy is preferred as it is associated with high cost and poor patient satisfaction (1). Evidence suggesting that we should treat right and left colon equally has contributed to the further reduction in colostomy usage (6). Currently it is increasingly reserved for the rectal injuries (4).

In this study most of the colonic injuries were treated without colostomies (84.61\%). But the rate of colostomy was higher in rectal injuries (87.5\%) compared with the data of the study done by Steele et al. (Table 2). But in Steele's work, further 13\% led to stomas later due to failures of in-continuity. We did not have such complications.

The adequacy of diversion in loop colostomy is frequently debated $(2,3)$. Most of $(88.88 \%$ of colostomies) the patients in our study were with loop colostomies. None of them had inadequate diversion leading to complications. But this may not be adequate in significantly large rectal injuries. Morbidity with colostomy closure is less with loop colostomies.

Exteriorization of the injured bowel segment as colostomy is an acceptable and safe procedure for transverse and sigmoid colon (2). But in this study single sigmoid injury we had was treated with primary repair as it was small. Further we could have done primary repair for the patient who had exteriorization of the transverse colon due to haemodynamic instability, as this is not considered as an absolute contraindication.

Some of the colostomies in rectal injury patients could have avoided if per operative irrigation were done. But this is time consuming and inconvenient in a busy operating setup. Overall complication rate in our series is favourable with comparable studies (Table 3).

Single mortality in this study was due to an associated pelvic fracture

Table 1. Number of injuries according to the site

\begin{tabular}{|l|c|c|}
\hline Site & Number & Percentage \\
\hline Ascending colon & 7 & $33.33 \%$ \\
\hline Transverse colon & 4 & $19.04 \%$ \\
\hline Descending colon & 1 & $4.76 \%$ \\
\hline Sigmoid colon & 1 & $4.76 \%$ \\
\hline Rectum & 8 & $38.09 \%$ \\
\hline
\end{tabular}

Table 2. Percentage colostomy usage according to the site of injury

\begin{tabular}{|l|c|c|}
\hline Site & Steele et al & Our study \\
\hline Right colon & $19 \%$ & $0 \%$ \\
\hline Transverse colon & $25 \%$ & $25 \%$ \\
\hline Left colon & $36 \%$ & $50 \%$ \\
\hline Rectum & $65 \%$ & $87.5 \%$ \\
\hline
\end{tabular}

Table 3. Morbidity rates of comparable studies

\begin{tabular}{|l|c|}
\hline & Morbidity \\
\hline Duncan J E et al & $48 \%$ \\
\hline Demetriades et al (colonic injuries only) & $19 \%$ \\
\hline Mickevicius et al & $45.2 \%$ \\
\hline Our study & $14.28 \%$ \\
\hline
\end{tabular}




\section{References}

1. Brasel KJ, Borgstrom DC, Weigelt JA. Management of penetrating colon trauma: a cost utility analysis. Surgery 1999; 125(5): 471-9.

2. Sherif SH, Demis WJ. Management of colonic and rectal injuries. CMA Journal 1979; 120: 1387-91.

3. Philip JH, Erwin RT. Management of colon injuries. Surgical Clinics of North America 1990; 70: 561-73.

4. Gonzalez RP, Turk B, Surgical options in colorectal injuries. Scandinavian Journal of Surgery 2002; 91(1): 87-91.

5. Duncan JE, Corwin CH, Sweeny WB et al. management of colorectal injuries during
Operation Iraqi Freedom: pattern of stoma usage. Journal of Trauma 2008; 64(4): 1043-7.

6. Thompson JS, Moore EE, Moore JE. Comparison of penetrating injuries of the right and left colon. Annals Surgery 1981;193(4): 414-8.

7. Steele SR, Wolcott KE, Mullenix PS, et al. Colon and rectal injuries during Operation Iraqi Freedom: are there any changing trends in management or outcome. Disease of Colon and Rectum 2007; 50(6): 870-7.

8. Demetriades D, Pantanowitz D, Charalambides D. Gun shot wounds of the colon: role of primary repair. Annals of the Royal College of Surgeons of England 1992; 74: 381-84.

9. Mickevicius A, Kligaite J, Jamelis A, et al. Penetrating colorectal trauma: index of severity and results of treatment. Medicina 2003; 39(6): 562-9. 